九州大学学術情報リポジトリ

Kyushu University Institutional Repository

Genotypic differences in root traits of rice (Oryza sativa L.) seedlings grown under different soil environments.

Matsuo, Naoki

Graduate school of Bioresource and Bioenvironmental Science, Kyushu University

Mochizuki, Toshihiro

Faculty of Agriculture of Agriculture, Kyushu University

http://hdl. handle. net/2324/1790490

出版情報 : Plant Root. 3, pp.17-25，2009-06. Japanese Society for Root Research バージョン:

権利関係: (C)2009, Plant Root（JSRR） 


\title{
Genotypic differences in root traits of rice (Oryza sativa L.) seedlings grown under different soil environments
}

\author{
Naoki Matsuo ${ }^{1}$ and Toshihiro Mochizuki ${ }^{2}$ \\ ${ }^{1}$ Graduate school of Bioresource and Bioenvironmental Science, Kyushu University, 111 Harumachi, Kasuya-chou, \\ Kasuya-gun, Fukuoka, 811-2307 Japan \\ ${ }^{2}$ Fuclty of Agriculture, Kyushu University, 111 Harumachi, Kasuyachou, Kasuyagun, Fukuoka, 811-2307 Japan \\ Corresponding author: N. Matsuo, E-mail: n_matsuo@farm.kyushu-u.ac.jp, Phone: +81-92-612-2862, Fax: \\ $+81-92-612-2872$
}

Received on July 11, 2008; Accepted on March 4, 2009

\begin{abstract}
We investigated mainly root traits of rice (Oryza sativa L.) seedlings grown under four soil conditions (i.e. anaerobic, aerobic, low and high soil density) in thin and long transparent polyvinyl chloride tubes for 21 days. Using 70 rice varieties from four agricultural ecotypes (i.e. japonica upland (JU), japonica lowland (JL), indica upland (IU), and indica lowland (IL)), we examined the effects of genotypes, environment and their interaction on seminal root length (SRL), seminal root thickness (SRT), number of crown roots (NCR), root and shoot dry weight (RDW and SDW) and root/shoot ratio (R/S ratio). The significant effects of genotype, environment and their interaction on all the traits were detected. Rice varieties could be clearly classified into their own ecotypes by a combined principle component analysis (PCA) for NCR, SRT, and SDW. Seventy rice varieties could be separated into upland and lowland varieties based on the scores of the first principle component (PC) and, among upland varieties, JU varieties could be separated from IU varieties based on the scores of the second PC. JU varieties had longer and thicker seminal roots than the other varieties in aerobic soil conditions, indicating that these varieties may be more suitable for aerobic soil conditions from the view point of the seedling establishment.
\end{abstract}

Keywords: $G \times E$ interaction, lowland rice, principle component analysis, root traits, upland rice

Abbreviations: DAS, days after sowing; $G \times E$ interaction, genotype $\times$ environment interaction; IL, indica lowland; IU, indica upland; JL, japonica lowland; JU, japonica upland; NCR, the number of crown roots; PCA, principle component analysis; RDW, root dry weight; R/S ratio, root/shoot ratio; SDW, shoot dry weight; SRL, seminal root length; SRT, seminal root thickness

\section{Introduction}

Rice is cultivated under four different land types in the world, and the distribution of land usage for rice cultivation as of 2004-2006 is as follows: irrigated, $57 \%$; rainfed lowland, $31 \%$; upland, $9 \%$; deepwater, 3\% (IRRI, 2009). Therefore, soil water conditions should largely differ among cultivation types; irrigated paddy condition is anaerobic, rainfed lowland, alternately anaerobic and aerobic, and upland, aerobic. As compared to the yield obtained under irrigated paddy conditions, that obtained under rainfed lowland and upland conditions is low and unstable. This is because the water supply largely depends on uncertain and uneven rainfall, resulting in large fluctuations of the soil moisture conditions. Drought stress is a major constraint to rice production and yield stability in rainfed regions (Evenson et al. 1996). It has been suggested that upland rice, which is usually cultivated under rainfed conditions, is more sensitive to water stress than other upland crops due to its shallow root system (Angus et al. 1983). Therefore, a deep root system is needed for acquiring water and nutrition from the relatively wet deep soil layer to obtain a stable yield under rainfed conditions. Upland rice varieties with deep root systems were noted to take up a considerable amount of water from the deeper soil layers during periods of water stress (Yoshida and Hasegawa 1982). Fukai and Cooper (1995) proposed that the genotypic variations in the root system in order to enhance the water-capture ability of the plant

Matsuo N and Mochizuki T 2009 Genotypic differences in root traits of rice (Oryza sativa L.) seedlings grown under different soil environments. Plant Root 3: 17-25. doi:10.3117/plantroot.3.17

Copyrights 2009, Plant Root (JSRR), www.plantroot.org 
could be an avenue for improving the drought tolerance of rice. Penetration ability of root system is one of the important traits to confer the deep root systems to rice plants (Nguyen et al. 1997). It is well known that soil mechanical impedance inhibits root growth in many plant species (Materechera et al. 1991). In rice, Nhan et al. (2006) assessed the root penetration ability of 72 rice varieties using a wax layer method and reported that upland varieties possessed higher penetration ability than lowland varieties. Further, they reported that japonica upland varieties had higher penetration ability than indica upland varieties. Other root traits, such as seminal and crown root developments, which were effective for rice plants to grow under drought and/or upland conditions, have been widely reported (Bañoc et al. 2000; Kondo et al. 2000; Zhang et al. 2001; Sharp, 2002 ).

The ability of roots to change developmentally and functionally in response to the changing conditions was suggested to be one of the most important traits for adaptation (Ingram et al. 1994; Yamauchi et al. 1996). Therefore, in addition to a deep root system, root morphological change to a given environment may be an important factor under rainfed conditions where soil moisture conditions often fluctuate. Although there are some reports on the phenotypic change of root morphology in response to changing soil conditions in rice (Luquet et al. 2005), and barley and wheat (Bingham et al. 1997, 2003), limited reports are available for this aspect, possibly due to its complexity of this feature and the laborious and time-consuming nature of investigations for root traits. Consequently, limited information is available regarding the relative effects of genotype, environment and their interaction on variations in root morphology. These problems may hinder the progress of plant breeding in terms of root-trait manipulation. More convenient and effective methods, which can deal with the large number of genotype and environment, should be developed to facilitate the selection of rice varieties that can adapt to several environmental conditions. Although there are few reports on root traits of the large number of varieties, Laffite et al. (2001) investigated root traits of 136 rice varieties under an irrigated aerobic condition, and demonstrated that root traits were related with agricultural ecotypes. Moreover, they reported that japonica varieties had thicker roots with wider vessels and high root/shoot ratio (R/S ratio), while indica varieties had thin roots with narrow vessels and low root/shoot ratio. Kato et al. (1992) compared 28 rice varieties which included lowland and upland types in terms of seminal root elongation rate, lateral root development, nodal root development and their xylem vessel dimension, and found a large genotypic variation. They also showed that upland rice varieties had longer seminal root and thicker root systems than lowland ones. Further, they classified 10 of 28 rice varieties by a principle component analysis (PCA) and relatively clearly separated upland varieties from lowland ones (Kato et al., 1992). In this way, classification of the varieties into some groups may be important to facilitate the selection of varieties for following studies or breeding. However, these studies were conducted under single environment. Therefore, it is unclear to what extent $\mathrm{G} \times \mathrm{E}$ interaction affects on root morphologies. Kondo et al. (2003) classified 11 rice varieties based on the behavior of root traits under three different sites. This approach should be useful to select varieties and traits toward specific environments, but few studies have focused on this aspect from the viewpoint of root traits.

In this study, we assessed root and shoot traits of 70 rice varieties with a simple and easy method under four soil environments (anaerobic, aerobic, and lowand high-soil density). Because it is difficult and time-consuming to investigate complicated traits, such as anatomical traits with a microscope, for many varieties, we investigated basic traits, i.e., seminal root length (SRL) and thickness (SRT), the number of crown roots (NCR), root and shoot dry weight (RDW and SDW) and R/S ratio. Then, we analyzed the effects of genotype, environment and $\mathrm{G} \times \mathrm{E}$ interaction on them. Further, we attempted to detect which environmental factors had the largest effects on the traits and to classify the 70 varieties with respect to each trait by the PCA.

\section{Materials and Methods}

\section{Plant material}

This study included 70 rice (Oryza sativa L.) varieties, namely, 16 japonica upland (JU), 30 japonica lowland (JL), 19 indica upland (IU) and five indica lowland (IL) varieties (Table 1).

\section{Growth conditions}

Four treatments were conducted to compare the effects of anaerobic and aerobic conditions (Anaerobic and Aerobic), and to compare the effects of soil hardness (low- and high-soil density, Low and High) on the root and shoot traits. The growth method was similar to that employed by Kato et al. (1991) with some modification. Transparent polyvinyl chloride (PVC) tubes (length $50 \mathrm{~cm}$; inner diameter $1.6 \mathrm{~cm}$ ) were sealed at the bottom with perforated packing tape and filled with vermiculite or clay loam soil $(41.1 \%$ sand, $34.3 \%$ silt and $24.6 \%$ clay) with $0.18 \mathrm{~g}$ chemical fertilizer $\left(4 \% \mathrm{~N}, 4 \% \mathrm{P}_{2} \mathrm{O}_{5}\right.$ and $\left.4 \% \mathrm{~K}_{2} \mathrm{O}\right)$. In the first two treatments (Anaerobic and Aerobic), PVC tubes 
Table 1. Plant materials.

\begin{tabular}{|c|c|c|c|c|c|}
\hline Ecotype & Variety name & History & Ecotype & Variety name & History \\
\hline \multirow[t]{17}{*}{ japonica upland } & Rikuto Norin 6 & Improved & japonica lowland & Koshihikari & Improved \\
\hline & Rikuto Norin 12 & Improved & & Nishihomare & Improved \\
\hline & Rikuto Norin 22 & Improved & & Nipponbare & Improved \\
\hline & Rikuto Norin 24 & Improved & & Yumetsukushi & Improved \\
\hline & Rikuto Norin Mochi1 & Improved & & Shinriki & Traditional \\
\hline & Rikuto Norin Mochi 8 & Improved & & Hinohikari & Improved \\
\hline & Rikuto Norin Mochi 18 & Improved & & Norin 18 & Improved \\
\hline & Rikuto Norin Mochi 20 & Improved & & Reiho & Traditional \\
\hline & Rikuto Norin Mochi 25 & Improved & & Shirobeniya & Traditional \\
\hline & Hataminori Mochi & Improved & & Asahi & Traditional \\
\hline & Minamihata Mochi & Improved & & Akenohoshi & Improved \\
\hline & Owarihata Mochi & Improved & & Akebono & Improved \\
\hline & IRAT 109 & Improved & & Chiyonishiki & Improved \\
\hline & IRAT117 & Improved & & Akamoro & Traditional \\
\hline & Azucena & Traditional & & Toyonishiki & Improved \\
\hline & Sensho & Traditional & & Domannaka & Improved \\
\hline & & & & Haenuki & Improved \\
\hline \multirow[t]{19}{*}{ indica upland } & Beo dien & Traditional & & Miyazakizairai & Traditional \\
\hline & Beo san van & Traditional & & Aikoku & Traditional \\
\hline & СТ6510-24-1-2 & Improved & & Lemont & Improved \\
\hline & Ep hat dai & Traditional & & Shiranui & Improved \\
\hline & Ep hat den & Traditional & & Tsukushiwase & Improved \\
\hline & Ep hat to & Traditional & & Sengoku & Improved \\
\hline & Ep hat tron & Traditional & & Akihikari & Improved \\
\hline & IR47686-30-3-2 & Improved & & Kamenoo & Traditional \\
\hline & IR57920 & Improved & & Nekken 2 & Improved \\
\hline & IR71525-19-1-1 & Improved & & Zuiho & Improved \\
\hline & Khau kai & Traditional & & Taichung 65 & Improved \\
\hline & Khau ken & Traditional & & Kinmaze & Improved \\
\hline & Khau linh & Traditional & & Asominori & Improved \\
\hline & LC-90-12 & Traditional & & & \\
\hline & Mo do & Traditional & indica lowland & IR 36 & Improved \\
\hline & Nep bao lac & Traditional & & DV 85 & Improved \\
\hline & Nep khau non & Traditional & & HA 2 & Traditional \\
\hline & Te rau & Traditional & & IR 24 & Improved \\
\hline & UPLRi-7 & Improved & & Bhadua & Traditional \\
\hline
\end{tabular}

were filled up to $3.5 \mathrm{~cm}$ from the top with approximately $25 \mathrm{~g}$ of vermiculite (bulk density, $0.25 \mathrm{~g} \mathrm{~cm}^{-3}$ ) that had been passed through a $4 \mathrm{~mm}$ sieve mesh. Only for Aerobic, $30 \mathrm{~mL}$ water was added to wet all the vermiculite in the tubes. For both treatments, clay loam soil with a gravimetric moisture content of approximately $13 \%$ was added over the vermiculite up to $2.0 \mathrm{~cm}$ from the top in order to sow seeds. In the next two treatments (Low and High), the clay loam soil used was sieved through a $4 \mathrm{~mm}$ mesh screen and dried in an oven. Gravimetric moisture content of the soil was adjusted at $13 \%$ before use. The PVC tubes were filled with this soil up to $2.0 \mathrm{~cm}$ from the top. The bulk density was set at $1.10 \mathrm{~g} \mathrm{~cm}^{-3}$ and $1.34 \mathrm{~g}$ $\mathrm{cm}^{-3}$ for Low and High treatment, respectively. On commencement of the experiment, the water potential of the soil was $-0.43 \mathrm{MPa}$ (measured with WP4; Decagon Devices Inc., Pullman, WA, USA). The soil 


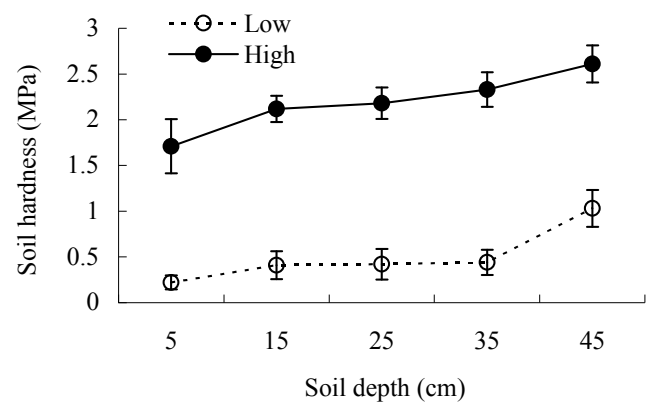

Fig. 1. Soil hardness along the soil depth. The open circles and dotted line indicate the Low treatment and closed circles and solid line indicate the High treatment. Data are presented as the mean \pm S.D. $(n=5)$.

hardness was measured along the depth using a soil hardness meter (DIK-5561, Daiki Rika Kogyo, Saitama, Japan), and the values obtained are shown in Fig. 1.

Seeds were soaked in water at $30{ }^{\circ} \mathrm{C}$ for $72 \mathrm{~h}$. One seed was sown in each tube at $1.0 \mathrm{~cm}$ below the soil surface. For Anaerobic, the PVC tubes were placed in a steel tank $(110 \times 44 \times 48 \mathrm{~cm}$, Fig. 2), while for the other three treatments, the PVC tubes were placed in another steel tank $(110 \times 90 \times 48 \mathrm{~cm})$. The water level was maintained at the position of $5 \mathrm{~mm}$ above the soil surface and at $5 \mathrm{~cm}$ up from the bottom of the tubes in the former and latter tanks, respectively. Small holes $(2.0 \mathrm{~cm}$ in inner diameter), the distance between the holes was $2 \mathrm{~cm}$, were made toward the top and bottom of the tank to keep the tubes in place at an inclination of approximately 10 degrees. For Aerobic, Low and

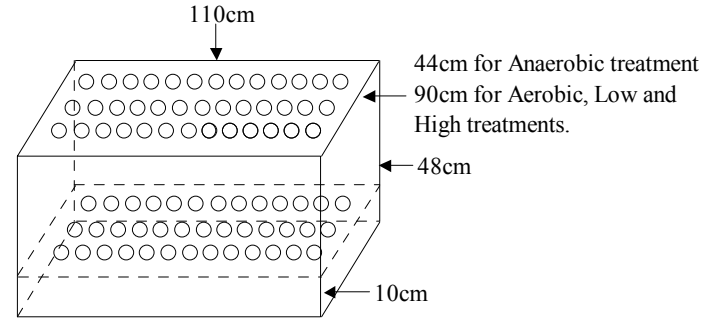

Fig. 2. Simplified diagram of the experimental tank used in this study.

High, the top of the tube was covered with paraffin paper to prevent excessive evaporation from the soil surface. On seed germination, a small hole was punctured in the paraffin paper to allow the shoots to elongate outside th tube. The plants were grown in a climate-controlled chamber (day, $12 \mathrm{~h}$ at $30^{\circ} \mathrm{C}$; night, $12 \mathrm{~h}$ at $24^{\circ} \mathrm{C}$; light intensity, approximately $180 \mu \mathrm{mol}$ $\mathrm{m}^{-2} \mathrm{~s}^{-1}$ ). For Anaerobic, tubes were placed randomly, and for the other three treatments, a randomized complete block design was used. Three replications were performed for each treatment.

\section{Measurements}

Shoots were cut at the soil surface at 21 days after sowing (DAS), and roots were removed from PVC tubes and washed carefully with tap water. Then, SRL was measured and NCR was counted. SRT was measured at $1.0 \mathrm{~cm}$ from the root tip by using a

Table 2. Mean values of seminal root length (SRL), number of crown roots (NCR), seminal root thickness (SRT), root dry weight (RDW), shoot dry weight (SDW) and root/shoot ratio (R/S ratio) in each treatment and results of two-way ANOVA in each trait. .

\begin{tabular}{|c|c|c|c|c|c|c|}
\hline & $\mathrm{SRL}(\mathrm{cm})$ & NCR & SRT (mm) & RDW (mg) & SDW (mg) & $\mathrm{R} / \mathrm{S}$ ratio \\
\hline Anaerobic & $187 \mathrm{c}^{\mathrm{a}}$ & $14.5 \mathrm{a}$ & $0.19 \mathrm{c}$ & $13.5 \mathrm{a}$ & $92.0 \mathrm{a}$ & $0.15 \mathrm{~b}$ \\
\hline Aerobic & 364 a & $2.1 \mathrm{~b}$ & $0.30 \mathrm{a}$ & $8.2 \mathrm{~b}$ & $45.0 \mathrm{c}$ & $0.22 \mathrm{a}$ \\
\hline Low & 358 a & $1.0 \mathrm{~b}$ & $0.27 \mathrm{~b}$ & $7.0 \mathrm{bc}$ & $41.8 \mathrm{c}$ & $0.20 \mathrm{a}$ \\
\hline High & $323 \mathrm{~b}$ & $1.0 \mathrm{~b}$ & $0.30 \mathrm{ab}$ & $5.7 \mathrm{c}$ & $51.8 \mathrm{~b}$ & $0.12 \mathrm{~b}$ \\
\hline Genotype & $6.02 * * * b$ & $12.24 * * *$ & $7.19 * * *$ & $8.74 * * *$ & $5.47 * * *$ & $3.63 * * *$ \\
\hline Environment & $574.10 * * *$ & $3333.00 * * *$ & $211.78 * * *$ & $767.72 * * *$ & $296.31 * * *$ & $89.97 * * *$ \\
\hline $\mathrm{G} \times \mathrm{E}$ & $2.66 * * *$ & $7.40 * * *$ & $3.38 * * *$ & $5.31 * * *$ & $3.66 * * *$ & $3.80 * * *$ \\
\hline
\end{tabular}

Factors influencing these traits are also expressed as F-values.

${ }^{a}$ Means followed by the same letters were not significantly different among treatments at $\mathrm{P}<0.05$ by Tukey's test $(\mathrm{n}=70)$.

$\mathrm{b} * * *$ indicates significance at $\mathrm{P}<0.001$. 
microscope. Thereafter, samples were dried at $70{ }^{\circ} \mathrm{C}$ for at least $72 \mathrm{~h}$, and SDW and RDW were determined. $\mathrm{R} / \mathrm{S}$ ratio was calculated by dividing RDW by SDW.

\section{Data analyses}

Data were analyzed by a two-way analysis of variance (ANOVA). Then, Tukey's test was performed to separate means among treatments for each trait. Each variety was separated into its own agricultural ecotypes and Scheffe's F-test was conducted to separate means among agricultural ecotypes in each treatment and trait. Genotype means were used for the PCA with respect to each trait. According to the factor loadings of the first and second principal components (PCs), the environment factors which explained for the first and second PCs were analyzed for each trait. Then, rice varieties were plotted on a scatter diagram with respect to each trait, based on the scores of the first and second PC. Finally, 70 rice varieties were plotted on a scatter diagram based on a combined PCA operated for phenotypic data of the selected traits. Each data analysis was conducted using UNISTAT Ver. 5.6 (UNISTAT Ltd., London, UK).

\section{Results}

\section{Shoot and root growth}

Two-way ANOVA indicated significant $(\mathrm{P}<0.001)$ effects of genotype and environment on all the traits (Table 2). Further, there was a significant $(\mathrm{P}<0.001)$ effect of $\mathrm{G} \times \mathrm{E}$ interaction on all the traits. Mean values of SRL and SRT in Aerobic were the largest among four soil conditions and those in Anaerobic were significantly lower than those of the other three soil conditions. NCR, RDW and SDW in Anaerobic treatment were significantly higher than those in the other soil conditions. R/S ratio in Aerobic and Low were significantly higher than those in Anaerobic and High.

Table 3 shows the mean values of root and shoot traits with respect to each agricultural ecotype under each treatment. Among agricultural ecotypes, JU varieties tended to have longer SRL in aerobic conditions (i.e. Aerobic, Low and High) than the other ecotypes, but shorter in Anaerobic. Although IU varieties showed the largest SRT among ecotypes in Anaerobic, JU varieties tended to have larger SRT in aerobic conditions. For NCR, lowland varieties tended to have larger values than upland varieties in all the treatments. For RDW and SDW, however, consistency was not observed among agricultural ecotypes in all the treatments. Upland varieties tended to have higher $\mathrm{R} / \mathrm{S}$ ratio than lowland varieties.
Table 3. Mean values of seminal root length (SRL), number of crown roots (NCR), seminal root thickness (SRT), root dry weight (RDW), shoot dry weight (SDW), and root/shoot ratio (R/S ratio) in each treatment and ecotype.

\begin{tabular}{|c|c|c|c|c|}
\hline & Anaerobic & Aerobic & Low & High \\
\hline \multicolumn{5}{|c|}{ SRL (mm) } \\
\hline JU & $155 \mathrm{~b}^{\mathrm{a}}$ & 378 a & 393 a & $360 \mathrm{a}$ \\
\hline $\mathrm{JL}$ & $202 \mathrm{a}$ & 348 a & $358 \mathrm{~b}$ & $329 \mathrm{ab}$ \\
\hline IU & $194 \mathrm{a}$ & $370 \mathrm{a}$ & $339 \mathrm{ab}$ & $286 \mathrm{~b}$ \\
\hline IL & $168 \mathrm{ab}$ & 390 a & $318 \mathrm{~b}$ & $312 a b$ \\
\hline \multicolumn{5}{|c|}{ NCR (nr) } \\
\hline JU & $13.6 \mathrm{~b}$ & $0.5 \mathrm{a}$ & $0.1 \mathrm{c}$ & $0.3 \mathrm{~b}$ \\
\hline $\mathrm{JL}$ & $17.1 \mathrm{a}$ & $2.6 \mathrm{a}$ & $1.7 \mathrm{a}$ & $1.7 \mathrm{a}$ \\
\hline IU & $9.8 \mathrm{c}$ & $2.9 \mathrm{a}$ & $0.5 \mathrm{bc}$ & $0.4 \mathrm{~b}$ \\
\hline IL & $19.4 \mathrm{a}$ & $1.4 \mathrm{a}$ & $1.3 \mathrm{ab}$ & $1.2 \mathrm{ab}$ \\
\hline \multicolumn{5}{|c|}{ SRT (mm) } \\
\hline JU & $0.19 \mathrm{~b}$ & $0.32 \mathrm{a}$ & $0.34 \mathrm{a}$ & $0.37 \mathrm{a}$ \\
\hline JL & $0.16 \mathrm{~b}$ & $0.29 \mathrm{a}$ & $0.25 \mathrm{~b}$ & $0.27 \mathrm{~b}$ \\
\hline IU & $0.23 \mathrm{a}$ & $0.30 \mathrm{a}$ & $0.26 \mathrm{~b}$ & $0.30 \mathrm{~b}$ \\
\hline IL & $0.15 \mathrm{~b}$ & $0.29 \mathrm{a}$ & $0.25 \mathrm{~b}$ & $0.23 \mathrm{~b}$ \\
\hline \multicolumn{5}{|c|}{ RDW (mg) } \\
\hline JU & $15.4 \mathrm{a}$ & $7.6 \mathrm{a}$ & $7.0 \mathrm{a}$ & $6.3 \mathrm{a}$ \\
\hline $\mathrm{JL}$ & $13.4 \mathrm{a}$ & $7.6 \mathrm{a}$ & $6.9 \mathrm{a}$ & $5.4 \mathrm{a}$ \\
\hline IU & $12.6 \mathrm{a}$ & $9.7 \mathrm{a}$ & $7.3 \mathrm{a}$ & $5.6 \mathrm{a}$ \\
\hline IL & $11.2 \mathrm{a}$ & $7.8 \mathrm{a}$ & $6.5 \mathrm{a}$ & $5.3 \mathrm{a}$ \\
\hline \multicolumn{5}{|c|}{ SDW (mg) } \\
\hline JU & $96.6 \mathrm{ab}$ & $37.7 \mathrm{~b}$ & $32.1 \mathrm{a}$ & $43.3 \mathrm{a}$ \\
\hline $\mathrm{JL}$ & $96.7 \mathrm{a}$ & $38.6 \mathrm{~b}$ & $43.0 \mathrm{a}$ & $55.0 \mathrm{a}$ \\
\hline IU & $76.0 \mathrm{~b}$ & $54.8 \mathrm{a}$ & $43.9 \mathrm{a}$ & $51.5 \mathrm{a}$ \\
\hline IL & $116.5 \mathrm{a}$ & $46.5 \mathrm{ab}$ & $45.1 \mathrm{a}$ & $59.0 \mathrm{a}$ \\
\hline \multicolumn{5}{|c|}{$\mathrm{R} / \mathrm{S}$ ratio } \\
\hline JU & $0.15 \mathrm{a}$ & $0.22 \mathrm{a}$ & $0.25 \mathrm{a}$ & $0.16 \mathrm{a}$ \\
\hline $\mathrm{JL}$ & $0.14 \mathrm{a}$ & $0.22 \mathrm{a}$ & $0.17 \mathrm{a}$ & $0.10 \mathrm{~b}$ \\
\hline IU & $0.16 \mathrm{a}$ & $0.23 \mathrm{a}$ & $0.24 \mathrm{a}$ & $0.12 \mathrm{~b}$ \\
\hline IL & $0.10 \mathrm{a}$ & $0.17 \mathrm{a}$ & $0.15 \mathrm{a}$ & $0.10 \mathrm{~b}$ \\
\hline
\end{tabular}

Means followed by the same letters were not significantly different among ecotypes at $\mathrm{P}<0.05$ by Scheffe's F-test ( $\mathrm{n}=16$ for JU, 30 for JL, 19 for IU and 5 for IL).

\section{$P C A$}

The PCA was performed for each root and shoot trait and the results are shown in Table 4. In all the traits, the first and second PCs accounted for approximately $70 \%$ of the total variation. Low and High treatments yielded almost identical values, with greater effects on the first component; this indicated that the difference of soil media (i.e. vermiculite vs. soil) caused different phenotypes among rice varieties. The main effects on the second component differed among the traits tested. The main effects on the second component were 
Table 4. Eigenvalue, proportion, and eigenvector of the principle components for seminal root length (SRL), number of crown roots (NCR), seminal root thickness (SRT), root dry weight (RDW), shoot dry weight (SDW), and root/shoot ratio $(\mathrm{R} / \mathrm{S}$ ratio)

\begin{tabular}{|c|c|c|c|c|c|c|c|}
\hline \multirow[b]{2}{*}{ Traits } & \multirow{2}{*}{$\begin{array}{l}\text { Principle } \\
\text { component }\end{array}$} & \multirow{2}{*}{ Eigenvalues } & \multirow{2}{*}{ Proportion (\%) } & \multicolumn{4}{|c|}{ Eigenvector } \\
\hline & & & & Anaerobic & Aerobic & Low & High \\
\hline \multirow[t]{2}{*}{ SRL } & 1 & 1.848 & 46.201 & 0.208 & 0.316 & 0.651 & 0.658 \\
\hline & 2 & 0.977 & 24.419 & 0.895 & -0.439 & 0.008 & -0.080 \\
\hline \multirow[t]{2}{*}{ NCR } & 1 & 2.2865 & 57.162 & 0.356 & 0.410 & 0.594 & 0.594 \\
\hline & 2 & 1.0679 & 26.696 & 0.738 & -0.653 & -0.115 & 0.123 \\
\hline \multirow[t]{2}{*}{ SRT } & 1 & 1.7396 & 43.489 & 0.355 & 0.331 & 0.599 & 0.637 \\
\hline & 2 & 1.0097 & 25.244 & 0.619 & 0.608 & -0.418 & -0.269 \\
\hline \multirow[t]{2}{*}{ RDW } & 1 & 1.6917 & 42.292 & 0.397 & 0.250 & 0.601 & 0.647 \\
\hline & 2 & 1.1416 & 28.541 & 0.540 & 0.707 & -0.384 & -0.247 \\
\hline \multirow[t]{2}{*}{ SDW } & 1 & 1.8887 & 47.218 & 0.340 & -0.086 & 0.661 & 0.664 \\
\hline & 2 & 0.9972 & 24.929 & 0.107 & 0.991 & 0.082 & -0.007 \\
\hline \multirow[t]{2}{*}{$\mathrm{R} / \mathrm{S}$ ratio } & 1 & 2.0149 & 50.373 & -0.423 & -0.505 & 0.550 & 0.514 \\
\hline & 2 & 1.1270 & 28.175 & 0.618 & 0.442 & 0.407 & 0.507 \\
\hline
\end{tabular}

observed in Anaerobic for SRL and R/S ratio, both Anaerobic and Aerobic for NCR and SRT, Aerobic for RDW and SDW.

The rice varieties used were plotted on scatter diagram based on the scores of first and second PCs for each trait and results are shown in Fig. 3. Among the traits investigated, rice varieties could be clearly classified into their own agricultural ecotypes for NCR, SRT and SDW (Fig.3 B, C, E). Rice varieties were located separately on the scatter diagram for the other traits. For NCR, varieties which had large values of $\mathrm{X}$ axis showed larger NCR in Low and High, and varieties which had large values of $\mathrm{Y}$ axis showed larger NCR in Anaerobic but smaller in Aerobic. For SRT, varieties which showed large values of $X$ axis possessed larger SRT in Low and High, and varieties which showed large values of $Y$ axis possessed larger SRT in Anaerobic and Aerobic. For SDW, varieties which showed large values of $\mathrm{X}$ axis indicated larger SDW in Low and High, and varieties which showed large values of $\mathrm{Y}$ axis indicated larger SDW in Aerobic.

We selected the NCR, SRT and SDW from the classification results of 70 rice varieties for each trait, and operated the combined PCR including phenotypic data of these three traits under four soil conditions (Table 5). The cumulative contribution of the first three PCs was $65.4 \%$. The first $\mathrm{PC}$ had higher positive correlation with NCR in Low and High and negative correlation with SRT in Low and High. The second PC showed higher positive correlation with NCR and in Anaerobic and negative correlation with NCR and SDW in Aerobic, and SRT in Anaerobic. The third PC indicated higher positive correlation with SRT in Aerobic and SDW in Low and High.

Fig. 4 shows the scatter diagram of the scores of the first and second PCs obtained by the combined PCA. Varieties which had large values of $\mathrm{X}$ axis showed larger NCR in Low and High and smaller SRT in Low and High, and varieties which had large values of $\mathrm{Y}$ axis showed larger NCR in Anaerobic, smaller NCR in Aerobic, smaller SRT in Anaerobic, larger SDW in Anaerobic, and smaller SDW in Aerobic. Each variety could be clearly separated into its own agricultural ecotypes; JU varieties were located on second quadrate; IU varieties, third quadrate; JL and IL varieties, first and fourth quadrates. 

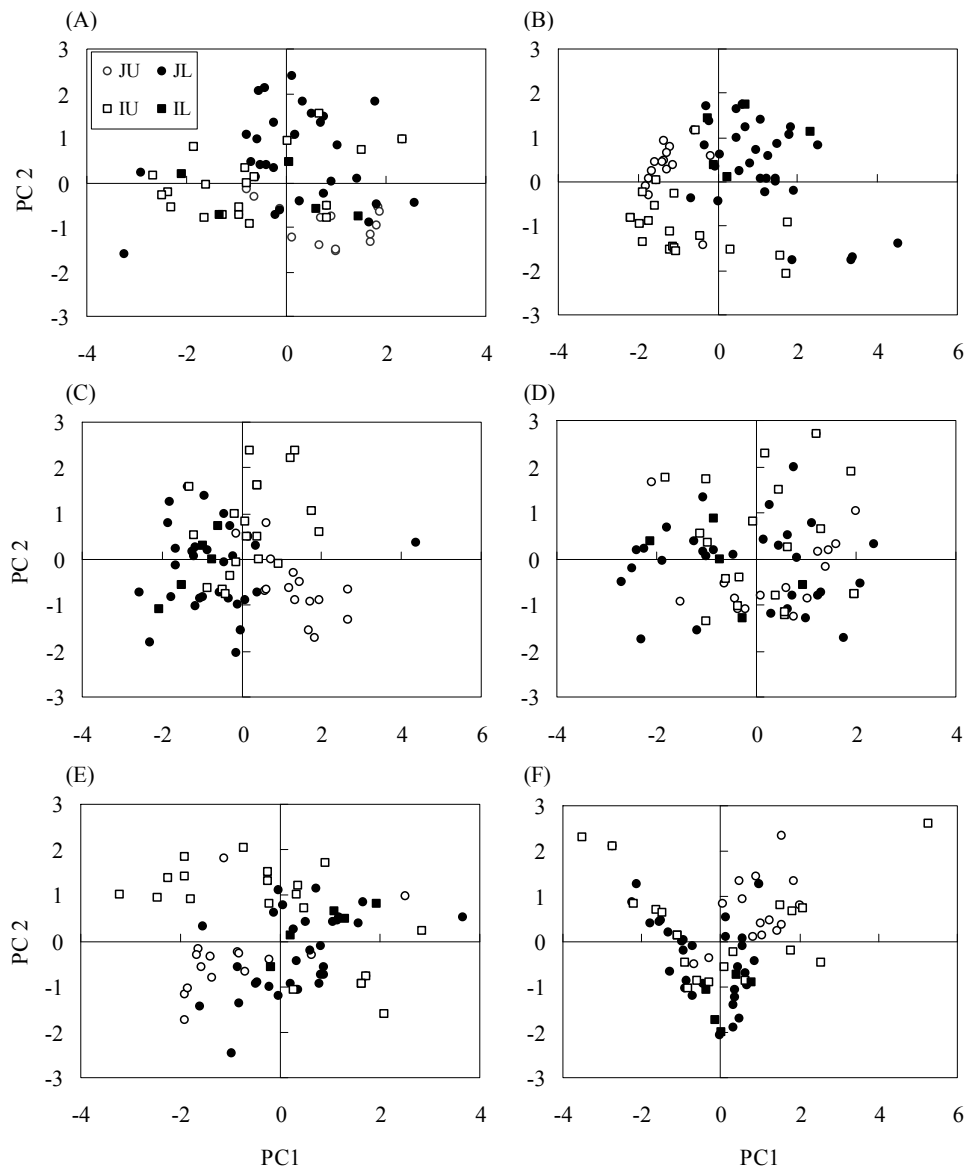

Fig. 3. Classification of 70 rice varieties based on the scores of the first and second PC for seminal root length (A), number of crown roots (B), seminal root thickness $(\mathrm{C})$, root dry weight (D), shoot dry weight (E), and root/shoot ratio (F).

\section{Discussion}

In the present study, two-way ANOVA revealed significant effects of genotype, environment and $\mathrm{G} \times \mathrm{E}$ interaction on root and shoot traits (Table 2). Further, it was found that the soil environment, especially the difference of soil media had the largest effect on all the traits tested (Table 4).

Lowland varieties could be separated from upland ones based on the scores of the first PC and upland varieties could be separated into japonica and indica varieties based on the scores of the second $\mathrm{PC}$ by the combined PCA (Fig. 4). Factor loadings of NCR and SDW were positive values and that of SRT was negative values for the first PC regardless of the treatments (Table 5). These results indicate that lowland varieties had larger NCR and SDW than upland ones, while thinner SRT regardless of soil environments. Although lowland varieties tended to have larger NCR than upland ones, RDW was not significantly different between lowland and upland varieties in all the treatments (Table 3), probably

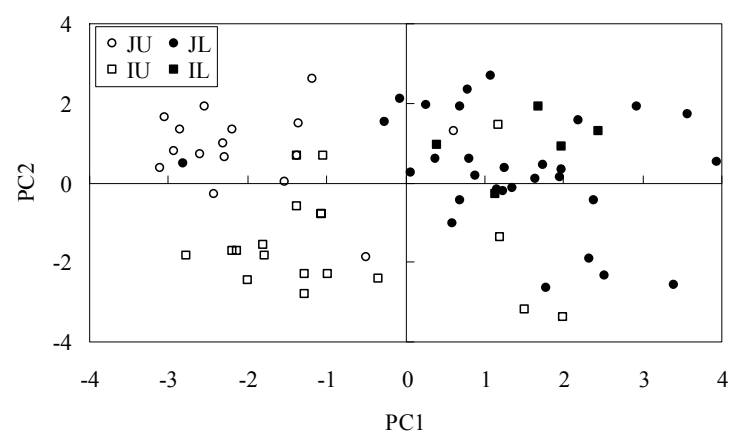

Fig. 4. Classification of 70 rice varieties based on the scores of the first and second PC by the combined PCA for the selected traits.

because upland varieties had thicker root systems and larger number of lateral roots. Previous study has also demonstrated that upland varieties had thicker root systems and smaller NCR than lowland varieties in a hydroponic culture and aerobic conditions (Kondo et 
Table 5. Eigenvalue, proportion, and eigenvector of the first, second and third principle components for the selected traits.

\begin{tabular}{lccc}
\hline & \multicolumn{3}{c}{ Principle component } \\
\cline { 2 - 4 } & 1 & 2 & 3 \\
\hline \multicolumn{1}{c}{ Eigenvalue } & 3.57 & 2.46 & 1.81 \\
\hline \multicolumn{1}{c}{ Proportion } & 29.8 & 20.5 & 15.1 \\
\hline \multicolumn{1}{c}{ Parameter } & & & \\
NCR Anaerobic & 0.3007 & 0.4171 & -0.1707 \\
NCR Aerobic & 0.2422 & -0.4511 & -0.1133 \\
NCR Low & 0.3879 & -0.1210 & -0.0621 \\
NCR High & 0.4512 & 0.0017 & -0.1023 \\
SRT Anaerobic & -0.2574 & -0.3753 & 0.2131 \\
SRT Aerobic & -0.0975 & 0.0088 & 0.5612 \\
SRT Low & -0.3318 & 0.3120 & 0.0038 \\
SRT High & -0.3492 & 0.1172 & -0.0344 \\
SDW Anaerobic & 0.1453 & 0.4542 & -0.1437 \\
SDW Aerobic & 0.0425 & -0.3725 & -0.2932 \\
SDW Low & 0.2847 & -0.0064 & 0.4959 \\
SDW High & 0.2919 & 0.1039 & 0.4792 \\
\hline
\end{tabular}

al. 2000, 2003). Upland rice varieties have been well known to be more resistant to drought stress than lowland ones. Thus, it may be concluded that the varieties which showed the negative scores of the first PC were more resistant to drought than those which showed the positive scores.

Upland varieties could be clearly separated into japonica and indica varieties based on the scores of the second PC. The second PC had higher positive correlation with NCR and SDW in Anaerobic, but negative with NCR and SDW in Aerobic (Table 5). Similarly, the second PC was positively correlated with SRT in Anaerobic, but negatively correlated with that in Low. These mean that JU varieties had larger NCR, thinner SRT and larger SDW than IU varieties in Anaerobic, while JU varieties had smaller NCR and larger SDW in Aerobic, and thicker SRT in Low than IU varieties, indicating the existence of $\mathrm{G} \times \mathrm{E}$ interaction on such traits. Significant difference of SRT was observed between JU and IU varieties in Low and High (Table 3). SRT of JU varieties in Low and High were much thicker than those in Anaerobic (0.19 in Anaerobic, 0.34 in Low and $0.37 \mathrm{~mm}$ in High), while SRT of IU varieties ranged 0.23 to $0.30 \mathrm{~mm}$. It was reported that japonica upland rice varieties had thicker roots than indica ones under aerobic conditions (Kondo et al. 2000; Lafitte et al. 2001). In the present study, JU varieties had larger SRT values than the other varieties in aerobic conditions (i.e. Aerobic, Low and High). Our result partly coincided with previous reports. Nhan et al (2006), who investigated root penetration ability of the same varieties as used in this study by using wax-layer methods, reported that the root penetration ability of JU varieties was significantly higher than that of IU varieties and the ability of root penetration was highly correlated with root thickness. Significant difference of root penetration ability between JU and IU varieties might cause the difference of SRL between JU and IU varieties (Table $3)$. Seminal root growth is important for the emergence and establishment of seedlings under upland conditions (Zhang et al. 2001; Sharp, 2002). Thus, it may be concluded that JU varieties are more adaptable to aerobic and hard soil conditions from the view point of initial plant establishment. However, the difference of SRL and SRT between JU and IU varieties could not explain the insignificant difference of RDW and SDW among varieties in Low and High. Therefore, future field experiments are needed to clarify the relationship between SRL and/or SRT and initial plant establishment under aerobic and hard soil conditions.

Because it is difficult to analyze root systems for many varieties under field conditions, approaches used in this study may be useful for the first selection of varieties. Further, to find interesting traits or varieties which are different from their own agricultural ecotypes may be also available for physiological studies or future breeding. For example, JL variety, "Lemont" was located in the second quadrate and was clearly separated from JL varieties even at seedling. This variety has been often used for study of drought resistance (Lilley and Fukai 1994a, 1994b, 1994c, Boonjung and Fukai 1996a, 1996b) and known to possess thicker root systems and larger root length density than the other lowland varieties (Lilley and Fukai 1994a, Ogata et al. 1996).

In conclusion, we detected the effects of genotype, environment and $\mathrm{G} \times \mathrm{E}$ interaction on root and shoot traits by using 70 rice seedlings. Also we found the difference of soil media had the largest effects on the traits. Moreover, we could clearly separate rice varieties into their own agricultural ecotypes based on the combined PCA for NCR, SRT and SDW. These approaches may lead to smooth selection of varieties for further studies or breeding. Future studies will be needed to investigate the root and shoot traits of plants grown in actual field conditions.

\section{References}

Angus JF, Hasegawa S, Hsiao TC, Liboon PS, Zandstra, HG 1983 The water balance of post-monsoonal dry land crops. J. Agric. Sci. 101: 699-710. 
Bañoc DM, Yamauchi A, Kamoshita A, Wade L J, Pardales Jr. J R 2000 Dry matter production and root system development of rice cultivars under fluctuating soil moisture. Plant Prod. Sci. 3: 197-207.

Bingham IJ, Bengough AG 2003 Morphological plasticity of wheat and barley roots in response to spatial variation in soil strength. Plant Soil 250: 273-282.

Bingham IJ, Blackwood JM, Stevenson EA 1997 Sute, scale and time-cource for adjustments in lateral root initiation in wheat following changes in $\mathrm{C}$ and $\mathrm{N}$ supply. Ann. Bot. 80: 97-106.

Boonjung H, Fukai S 1996a Effects of soil water deficit at growth stage on rice growth and yield under upland conditions. 1. Growth during drought. Field Crops Res. 48: $37-45$.

Boonjung H, Fukai S 1996b Effects of soil water deficit at growth stage on rice growth and yield under upland conditions. 2. Phenology, biomass production and yield. Field Crops Res. 48: 47-55.

Evenson RE, Herdt RW, Hossan M 1996 Rice Research in Asia: Progress and Priorities. CAB International, Wallingford, UK.

Fukai S, Cooper M 1995 Development of drought-resistant cultivars using physio-morphological traits in rice. Field Crops Res. 40: 67-86.

Ingram KT, Bueno FD, Namuco OS, Yambao EB, Betrouty CA 1994 Rice root traits for drought resistance and their genetic variation. In: Kirk GJD Ed., Rice root: Nutrient and water use. pp. 67-77.

IRRI 2009 Farm data-Rice ecosystems, 30. Distribution of rice crop area, by environment, 2004-2006. In: IRRI ed., IRRI World Rice Statistics. International Rice Research Institute, Los Baños, Phillipines. http://beta.irri.org/statistics (latest update: January 28, 2009)

Kato T, Yamauchi A, Kono Y 1991 Genotypic variations in major root traits for rice. Jpn. J. Crop Sci. 60 (Extra issue 1): 244-255. (in Japanese)

Kato T, Yamauchi A, Kono Y 1992 Genotypic variations in major root traits for rice: Comparison and Classification of root systems by principle component analysis. Jpn. J. Crop Sci. 61 (Extra issue 2): 157-158. (in Japanese)

Kondo M, Aguilar A, Abe J, Morita S 2000 Anatomy of nodal roots in tropical upland and lowland rice varieties. Plant Prod. Sci. 3: 437-445.

Kondo M, Pablico P P, Aragones D V, Agbisit R, Abe J, Morita S, Courtois B 2003 Genotypic and environmental variations in root morphology in rice genotypes under upland conditions. Plant Soil 255: 189-200.

Lafitte HR, Champoux MC, McLaren G, O'Toole J C 2001 Rice root morphological traits are related to isozyme group and adaptation. Field Crops Res. 71: 57-70.

Lilley JM, Fukai S 1994a Effect of timing and severity of water deficit on four diverse rice cultivars. I. Rooting pattern and soil water extraction. Field Crops Res. 37: 205-213.

Lilley JM, Fukai S 1994b Effect of timing and severity of water deficit on four diverse rice cultivars. II. Physiological responses to soil water deficit. Field Crops Res. 37: 215-223.

Lilley JM, Fukai S 1994c Effect of timing and severity of water deficit on four diverse rice cultivars. III. Phenological development, crop growth and grain yield. Field Crops Res. 37: 225-234.

Luquet D, Zhang BG, Dingkuhn M, Dexet A, Clément-Vidal A 2005 Phenotypuc plasticity of rice seedling: Case of phosphorus deficiency. Plant Prod. Sci. 8: 145-151.

Materechera SA, Dexter AR, Alston AM 1991 Penetration of very strong soil by seedling roots of different plant species. Plant Soil 135: 31-41.

Nguyen HT, Babu RC, Blum A 1997 Breeding for drought resistance in rice: physiological and molecular genetics consideration. Crop Sci. 37: 1426-1434.

Nhan DQ, Thaw S, Matsuo N, Xuan TD, Hong NH, Mochizuki T 2006 Evaluation of root penetration ability in rice using the wax-layers and the soil cake methods. J. Fac. Agric., Kyushu Univ. 51: 251-256.

Ogata T, Matsue Y 1996 Studies on direct sowing culture of rice in northern Kyushu. II. Evaluation of lodging tolerance by crown root thickness during seedling stage. Jpn. J. Crop Sci. 65: 502-508. (in Japanese with English abstract)

Sharp RE 2002 Interaction with ethylene: Changing views on the role of abscisic in root and shoot growth responses to water stress. Plant Cell Environ. 25: 211-222.

Yamauchi A, Pardales JR Jr, Kono Y 1996 Dynamics of roots and nitrogen in cropping systems of the semi-arid tropics. In Ito et al. Eds., Root System Structure and its Relation to Stress Tolerance. Japan International Research Center for Agriculture Sciences, Tsukuba, Japan. pp. 211-233.

Yoshida S, Hasegawa S 1982 The rice root system: its development and function. In O'Toole J C, Eds., Drought Resistance in Crops with Emphasis on Rice. International Rice Research Institute, Los Baños, Phillipines. pp. 97-114.

Zhang WP, Shen XY, Wu P, Hu B, Liao CY 2001 QTLs and epistasis for seminal root length under a different water supply in rice (Oryza sativa L.). Theor. Appl. Genet. 103: $118^{-123 .}$

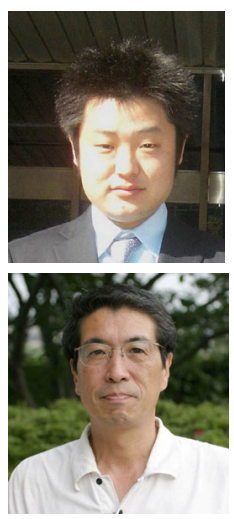

Dr. Naoki Matsuo's research interest is the morphological and functional changes of root systems in response to abiotic stress.

Dr. Toshihiro Mochizuki is an associate professor in the Department of Agroecology at the Faculty of Agriculture, Kyushu University. His research interest is G x E interaction for root growth of field crops. 